\section{Acute aortic dissection causing gastroduodenal and hepatic infarction}

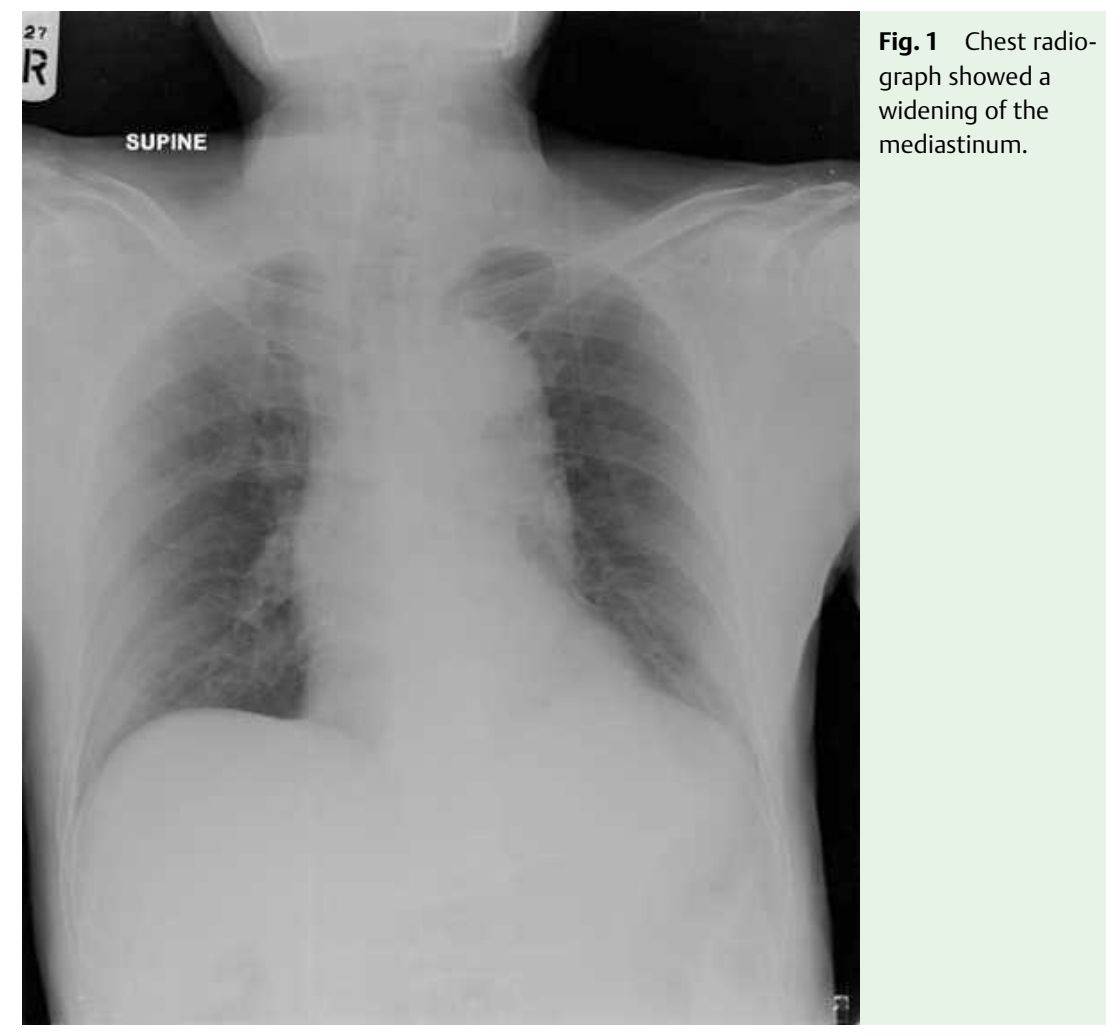

A 61-year-old man presented with severe acute epigastric pain for 15 hours followed by hematemesis. On arrival, the patient had high blood pressure, tachypnea, and tachycardia. Bowel sound was absent with mild abdominal distention. Nasogastric lavage revealed fresh blood. Complete blood count and liver function tests were unremarkable. Serum amylase and lipase were $836 \mathrm{U} / \mathrm{L}$ (normal range, 28-100 U/L), and $1870 \mathrm{U} / \mathrm{L}$ (normal range, 13-60 U/L), respectively. Chest radiography demonstrated a wide mediastinum ( $\bullet$ Fig. 1 ), and a plain film of the abdomen showed small-bowel ileus. He was sent for an emergent esophagogastroduodenoscopy. The findings are shown in $\bullet$ Fig. 2 and $\bullet$ Video 1. Gastroduodenal infarction was suspected and he was transferred for an emergent computed tomography (CT) scan of the whole abdomen. Acute aortic dissection (Stan-

\section{Video 1}

EGD revealed a normal esophagus whereas gastric mucosa showed ischemic congestion. ford type B) with hepatic and intestinal infarction was diagnosed ( $\bullet$ Fig. 3). After the patient had been stabilized, an exploratory laparotomy was performed. Gangrene of the gallbladder, spleen, descending and sigmoid colon were detected. Cholecystectomy, splenectomy, and left-half colectomy were performed. Within the same day, fenestration of infrarenal abdominal aorta to provide blood flow to the gut was also successfully carried out. After surgery the patient improved and experienced no further abdominal pain or bleeding.

We report a patient with acute aortic dissection presenting with acute upper gastrointestinal bleeding from gastroduodenal ischemia. In general, patients with uncomplicated dissecting aortic aneurysm type $B$ are best treated with conservative therapy [1]. However, our patient had a complicated course that compromised all major intra-abdominal aortic branches. Then an emergent aortic fenestration was indicated to effectively protect organs from gangrene. However, this
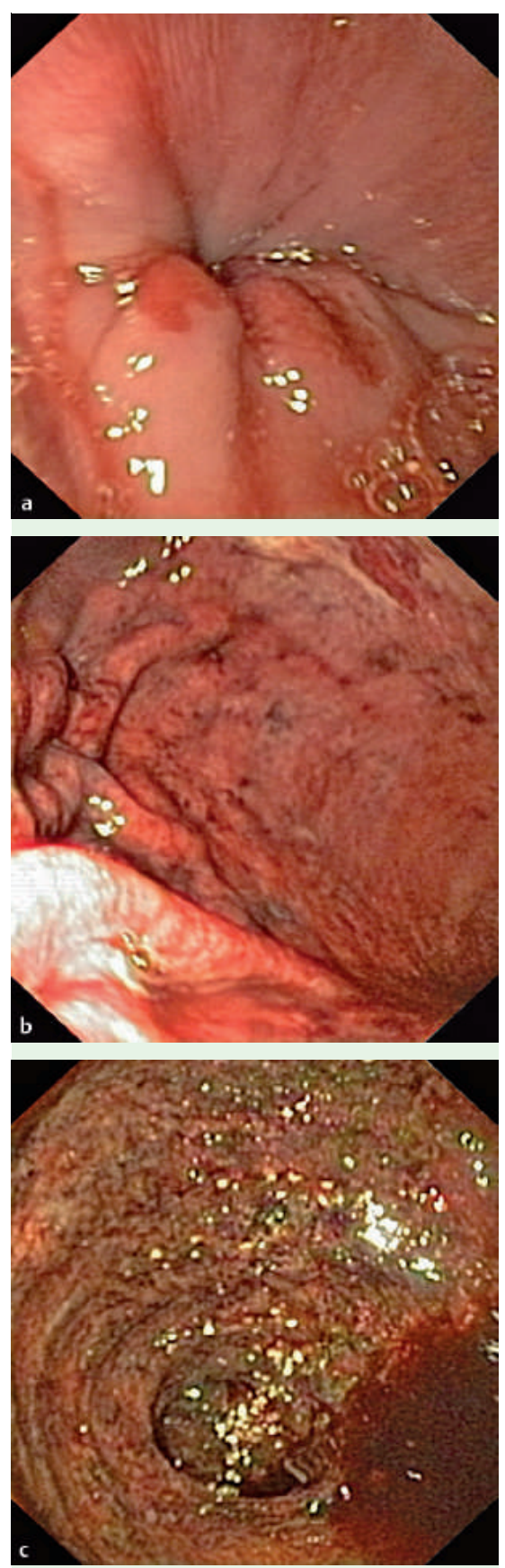

Fig. 2 a Esophagogastroduodenoscopy (EGD) revealed a normal esophagus. b EGD demonstrated gastric ischemia with congested mucosa. c Dark duodenal mucosa with submucosal hemorrhage secondary to infarction.

procedure still carries a high mortality rate [2]. By contrast, endovascular stent grafting is a less-invasive alternative and has a lower morbidity rate, especially in subacute and chronic dissection [3]. Unfortunately the outcome is not as good as surgery in acute dissection $[4,5]$.

Endoscopy_UCTN_Code_CCL_1AB_2AZ_3AD 


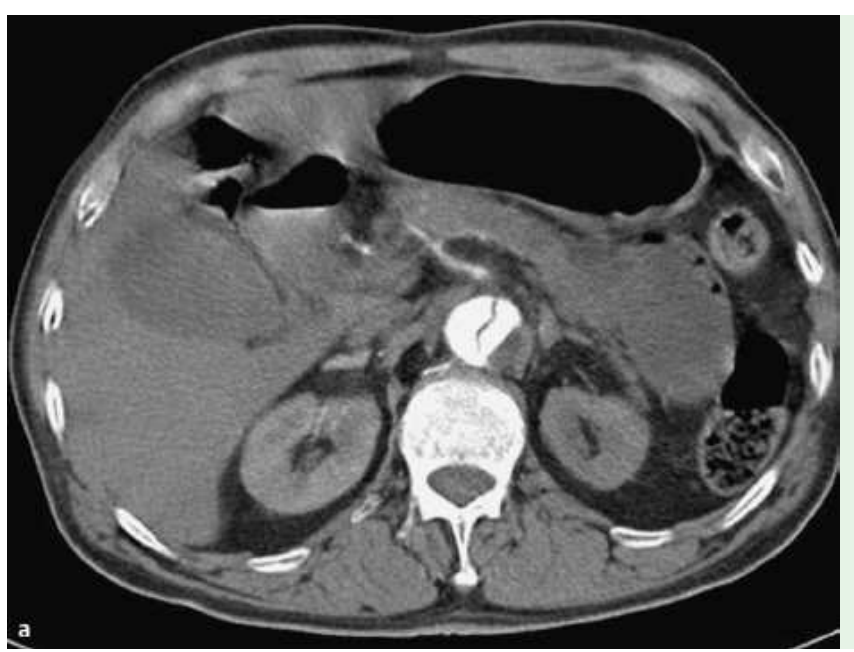

Fig. 3 a Computed tomography of the abdomen demonstrated a false track septum in the abdominal aorta. b Intravenous contrast computed tomography of the liver showed the area of left lobe infarction.

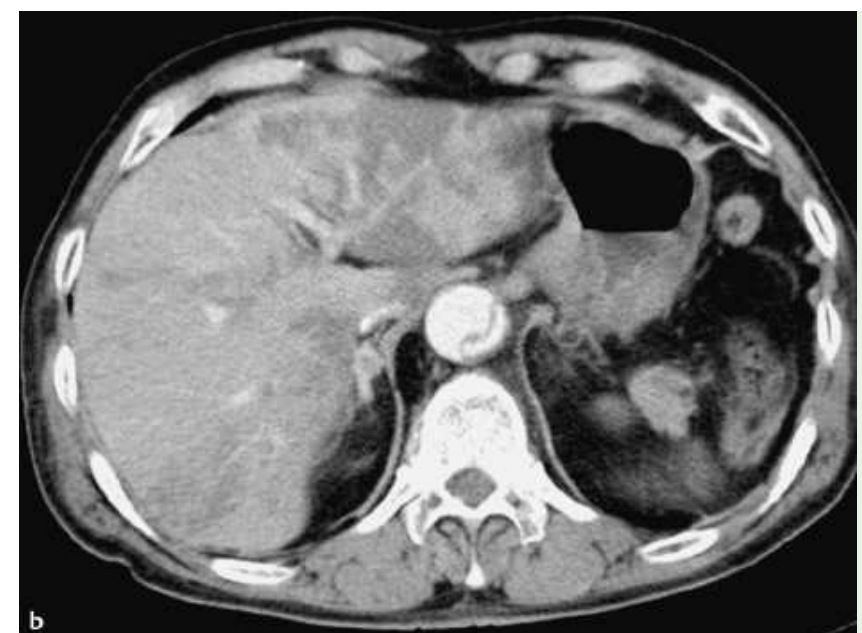

S. Jutaghokiat ${ }^{1}$, P. Angsuwatcharakon ${ }^{1}$, B. Imraporn ${ }^{1}$, P. Ongcharit ${ }^{2}$,

S. Udomsawaengsup ${ }^{2}$, R. Rerknimitr ${ }^{1}$

${ }^{1}$ Division of Gastroenterology, Department of Medicine, Chulalongkorn University Hospital, Bangkok, Thailand

2 Department of Surgery, Chulalongkorn University Hospital, Bangkok, Thailand

\section{References}

1 Estrera AL, Miller CC 3rd, Safi HJ et al. Outcomes of medical management of acute type B aortic dissection. Circulation 2006; 114 (1 Suppl): I384 - I389

2 Panneton JM, Teh SH, Cherry KJjr. et al. Aortic fenestration for acute or chronic aortic dissection: an uncommon but effective procedure. J Vasc Surg 2000; 32: 711 - 721

3 Nienaber CA, Fattori R, Lund G et al. Nonsurgical reconstruction of thoracic aortic dissection by stent-graft placement. New Engl J Med 1999; 340: 1539-1545

4 Dake MD, Kato N, Mitchell RS et al. Endovascular stent-graft placement for the treatment of acute aortic dissection. New Engl J Med 1999; 340: 1546 - 1552

5 Eggebrecht $H$, Nienaber CA, Neuhauser $M$ et al. Endovascular stent-graft placement in aortic dissection: a meta-analysis. Eur Heart J 2006; 27: 489-498

Bibliography

DOI $10.1055 / \mathrm{s}-0029-1214486$

Endoscopy 2009; 41: E88-E89

(c) Georg Thieme Verlag KG Stuttgart · New York . ISSN 0013-726X

Corresponding author

\section{R. Rerknimitr, MD}

Division of Gastroenterology

Department of Internal Medicine

Faculty of Medicine

Chulalongkorn University

Bangkok 10310

Thailand

Fax: +66-2-2527839

Rungsun@pol.net 